\title{
Co-creative place innovation in an arctic town
}

\author{
Malin Lindberg, Åsa Wikberg Nilsson and Eugenia Segerstedt \\ Department of Business Administration, Technology and Social Sciences, \\ Lulea University of Technology, Luleà, Sweden \\ Erik Hidman and Kristina L. Nilsson \\ Department of Civil, Environmental and Natural Resources Engineering, \\ Lulea University of Technology, Luleå, Sweden, and \\ Helena Karlberg and Johanna Balogh \\ Piteå Science Park, Piteå, Sweden
}

\section{Innovation in an arctic town}

\begin{abstract}
Purpose - The purpose of this paper is to shed light on co-creative approaches for place innovation in an Arctic town, based on the relocation of Kiruna's city center in northern Sweden. Three cases of co-creative innovation processes in Kiruna are investigated and compared: an R\&D project about local perceptions and visions of attractive urban environments; an R\&D project about norm-creative design principles for inclusive and attractive urban design; and an R\&D project about cross-industrial synergies for city center attractiveness.
\end{abstract}

Design/methodology/approach - The study's research design encompasses a comparative and participatory approach. The comparative approach implies investigation and comparison of three cases of cocreative innovation processes in Kiruna. The participatory approach implies joint development of new knowledge by researchers and local actors. The data consists of participatory observations of workshops and qualitative interviews with local actors.

Findings - The study reveals that the studied processes have harnessed the city center relocation as an opportunity to make Kiruna more attractive to residents and visitors, by using the co-creative approaches of Living Lab, Now-Wow-How and Norm-creative design. These approaches have enabled experts and local actors to jointly identify excluding patterns and norms in the relocation process and to envision inclusive and attractive (re-)configurations and (re-)conceptualizations of the future Kiruna.

Research limitations/implications - The results add to the academic strand of inclusive urban transformation, by providing insights into co-creative approaches for re-imagining an Arctic town in times of industrial and social change. New insights are provided regarding how the geographical, industrial and cultural identity of an Arctic town can be harnessed to envision new configuration, content and communication that is attractive and accessible for a diversity of residents and visitors.

Practical implications - The results highlight the potential to harness Arctic and rural characteristics in the promotion of urban attractiveness and public well-being, especially when combined with co-creative identification and transformation of excluding norms and patterns.

(C) Malin Lindberg, Åsa Wikberg Nilsson, Eugenia Segerstedt, Erik Hidman, Kristina L. Nilsson, Helena Karlberg and Johanna Balogh. Published by Emerald Publishing Limited. This article is published under the Creative Commons Attribution (CC BY 4.0) licence. Anyone may reproduce, distribute, translate and create derivative works of this article (for both commercial and non-commercial purposes), subject to full attribution to the original publication and authors. The full terms of this licence may be seen at http://creativecommons.org/licences/by/4.0/legalcode

The research in this article was funded by VINNOVA, The Swedish Retail and Wholesale Council (Handelsrådet), The R\&D Fund of the Swedish Tourism and Hospitality Industry (BFUF), Hjalmar Lundbohm Research Center and Sparbanken Nord.

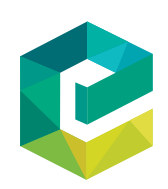

Journal of Place Management and Development Vol. 13 No. 4,2020 pp. $447-463$ pp. $447-463$
Emerald Publishing Limited $1753-8335$ DOI 10.1108/JPMD-02-2019-0009 
JPMD

13,4

Originality/value - The results provide new insights into how co-creative approaches may facilitate innovative and inclusive renewal of towns and cities in the Arctic and beyond.

Keywords Arctic, Co-creation, Norm-creative design, Place innovation, Urban transformation

Paper type Research paper

Introduction

Arctic cities and towns - generally located in rural regions with harsh climate, sparse population, long distances and scarce infrastructure - are struggling to find innovative solutions for attracting existing and potential residents, tourists, entrepreneurs and investors (Copus et al., 2017; Kostenius, 2018; Nyseth and Viken, 2009; Segerstedt and Abrahamsson, 2019). Their industrial base is thereto in flux, as traditional industries such as mining, forestry and hydro power. are becoming more technologically advanced, while service industries such as tourism and culture are rapidly expanding. The social composition of their local populations is simultaneously transformed, in regard to gender, ethnicity, age, etc. In Sweden's northernmost and most rural region, the mining town Kiruna is in search of solutions for maintained and improved attractiveness, while relocating their city center due to mining-related ground deformation. The relocation has been globally recognized in public media as a spectacular example of innovative urban transformation. To imagine new urban configurations and contents in Kiruna, several co-creative innovation processes have been conducted, where local actors - e.g. residents, entrepreneurs and civil servants - have been engaged together with researchers and other experts. These processes have generally had an inclusive agenda - envisioning an Arctic town that is attractive to multiple actors and involving a diversity of participants, perspectives and industries. This is part of a larger, global trend of inclusive innovation in general, and inclusive urban transformation in particular (Heeks et al., 2014; Nordregio, 2016).

Scholars in urban planning, innovation, design, etc., have increasingly highlighted cocreative approaches to urban transformation (Arefi, 2014; Brandsen et al., 2016; Chapman et al., 2017, 2018; Davies, 2015; Thomas, 2016). Previous publications in the Journal of Place Management and Development have, for example, explored the importance of local community involvement in public-private partnerships for innovative territorial governance (Argiolas et al., 2009), the necessity of stakeholder participation to harness collective definitions of place identity in place branding processes (Kavaratzis, 2012), residents' roles in co-creating place satisfaction (Källström and Hultman, 2018), and enactment of change outside formal planning processes through "community realized places” (Beza and Hernández-Garcia, 2018). Few publications in the journal have, however, explicitly addressed the Arctic context, and none has engaged with Kiruna's city center relocation. Studies published elsewhere have explored how Arctic challenges of harsh climate, sparse population, long distances and scarce infrastructure are transformed into opportunities for co-creating attractive, healthy and sustainable living environments (Chapman et al., 2017, 2018; Ebrahimabadi et al., 2015; Kenny, 2017; Kostenius, 2018). Kiruna's city center relocation has been studied in regard to planning processes, stakeholder interests, citizen involvement, etc. (Hidman, 2018; Nilsson, 2010a; Nilsson, 2009, 2010b; Sjöholm, 2016, 2017).

The current study adds to the academic strand of inclusive urban transformation, by its purpose to shed light on co-creative approaches for place innovation in an Arctic town, based on data from Kiruna's city center relocation. The study specifically aims to investigate and compare three co-creative innovation processes in Kiruna: 
(1) an R\&D project about local perceptions and visions of attractive urban environments;

(2) an R\&D project about norm-creative design principles for inclusive and attractive urban design; and

(3) an R\&D project about cross-industrial synergies for city center attractiveness.

The results provide further insight into how co-creative approaches may facilitate innovative and inclusive renewal in the Arctic and beyond.

The article is initiated with an outline of the theoretical framework of co-creative place innovation. This is followed by an account of the study's research design, with a comparative and participatory approach. Kiruna's city center relocation is thereafter depicted based on previous studies, before the data from the three cases is presented and discussed. Finally, conclusions are drawn regarding co-creative approaches for the reimagination of a peripheral Arctic town and implications are outlined for co-creative place innovation in other rural regions.

\section{Co-creative place innovation}

Studies of innovative transformation of cities, towns and other types of places are increasingly common among scholars in various disciplines (Arefi, 2014; Chapman et al., 2018; Davies, 2015; Kenny, 2017; Kostenius, 2018; Nordregio, 2016; Nyseth and Viken, 2009; Thomas, 2016). Some have conceptualized this in terms of place innovation, which is used as the main denomination in this study (Bernhard et al., 2018; Lindberg et al., 2015, 2017, 2018; Lundh Snis et al., 2017; Olsson and Bernhard, 2018). Place innovation refers to co-creative processes that innovatively interweave various actors, components and processes of a place, to improve its attractiveness to multiple local actors (Lindberg et al., 2018). It adds to similar concepts, such as place reinvention, place making, place management and place branding, by bridging urban studies and innovation studies. The notion of place innovation helps delineate the link between the identity of a place and its main components of configuration, content and communication. The identity stems from the place's cultural, social, economic and geographical situatedness. The configuration includes the architecture, design and other physical components of the place. The content encompasses the commercial, public and non-profit services and activities offered in the place. The communication regards the internal and external branding and marketing of the place. When innovatively combined, these components may appeal to existing and potential residents, tourists, entrepreneurs, investors and other actors. Place innovation studies highlight the need to bridge parallel processes of urban planning, destination design, business promotion, cultural development, social cohesion, etc., to match the all-encompassing scope of urban transformation (Bernhard et al., 2018; Lindberg et al., 2015, 2017, 2018; Lundh Snis et al., 2017; Olsson and Bernhard, 2018).

Urban transformation may be perceived as a combination of planned interventions and unplanned consequences of other ongoing processes (Nyseth and Viken, 2009). Economic, political and symbolic transformations have been proven to impact the configuration and perception of places, just as much as physical ones do (Arefi, 2014; Brandsen et al., 2016; Granås, 2012; Nyseth and Viken, 2009; Thomas, 2016). It is further noticed that places are produced not only by professionals in urban planning but also by people living in and visiting them (Hidman, 2018). Public policy in Sweden and elsewhere increasingly prescribe involvement of local communities in planning processes (Nilsson, 2010b). This is part of a general promotion of social, ecological and economic sustainability in urban planning (Hidman, 2018; Johansson et al., 2016; Nilsson, 2017). Studies of inclusive innovation and 
JPMD 13,4

design highlight various approaches to broadened involvement in development processes, in regard to represented actors, applied perspectives and aspired outcomes (Heeks et al., 2014; Lindberg, 2018; Nyseth and Viken, 2009; Wikberg Nilsson and Jahnke, 2018). These approaches challenge the traditional prioritization of technological expertise, industrial concerns and economic growth in such processes (Lindberg, 2018).

Inclusive innovation has been distinguished in terms of identification of previously unacknowledged or unaddressed needs among underrepresented or marginalized groups of people, as well as the development of solutions that improve the welfare and wellbeing among these groups (Lindberg, 2018). Inclusive innovation requires involvement of these groups in the process of identifying and addressing needs, as well as initiation of new interactions and synergies across organizational, sectorial and industrial borders. Inclusive innovation is enhanced by norm-critical and norm-creative design. Norm-critical design identifies and examines taken-for-granted assumptions and solutions, in regard to gender, ethnicity, disability, age and other social factors (Börjesson et al., 2016). Norm-creative design, in turn, creates alternative solutions to such assumptions and solutions, that enforces social inclusion and social sustainability (Wikberg Nilsson and Jahnke, 2018).

Inclusive design has been conceptualized in terms of "design for all", where products, services and information are designed to fit the widest range of users (Aragall and Montana, 2011). It is perceived as a design for human diversity, social inclusion and equality, enabling all people to have equal opportunities to participate in every aspect of society (The European Institute for Design and Diversity, 2020). Inclusive design has also been conceptualized in terms of "universal design", where all users' needs are met, regardless of physical, sensory, mental and intellectual abilities or characteristics (Aragall and Montana, 2011; Preiser and Ostroff, 2001). Universal design encompasses principles of equitable use, flexibility in use, simple and intuitive use, perceptible information, tolerance for errors, low physical effort, size and space regardless of body size, and posture or mobility (Connell et al., 1997).

Inclusive innovation and design generally involve co-creative processes, where experts (e.g. researchers or consultants) and local actors (e.g. residents, users or other concerned groups of people) jointly explore and address needs of improvement. Co-creation - and similar denominations such as "co-production" and "co-design" - has been described as "a new landscape of design", adding a user-perspective to traditional design expertise throughout the entire design process (Sanders and Stappers, 2008). It implies a shift from design centered around the product and technology to people's experiences and societal needs. This is expected to change "how we design, what we design, and who designs" as well as the tools and methods for doing this (ibid:15). The shift partly stems from the Scandinavian tradition of participatory workplace design in the 1970s, engaging industrial employees in the renewal of their workplaces. In parallel, a tradition of co-creation with customers emerged among American companies. Today, co-creation with local actors is regarded to be pivotal in several organizational and societal areas, including urban transformation (Källström and Hultman, 2018; Kavaratzis, 2012; Lindberg et al., 2018; Sanders and Stappers, 2008).

Co-creation is perceived to "mix up" the traditional roles of design experts and local actors (Sanders and Stappers, 2008). The former often take on the role of facilitator and provide tools for creativity, ideation and expression in the co-creative process, while the latter often take the position of expert of his/her experience in the generation of new knowledge, ideas and concepts. Three examples of practical approaches to co-creative innovation and design, that are specifically highlighted in this study, are Living Lab, NowWow-How and Norm-creative design. 
The Living Lab approach involves experts and local actors in the co-creation of new solutions to shared challenges and needs (Ståhlbröst, 2012). It aspires user impact and valuecreation for all involved actors, and allows new solutions to be developed and tested in reallife settings. There are different types of Living Labs, such as Organizational Living Lab with participants from a specific organization (e.g. managers, employees or volunteers) and Research Living Lab with participants from academia, industry and society.

The Now-Wow-How approach involves experts and local actors in a three-step process of co-creating new solutions to a specific challenge or need (Ericson and Törlind, 2013). The first step - Now - encompasses joint analysis of the existing situation. The second step Wow - encompasses joint envisioning of the preferred alternative future. The third step How - encompasses joint planning of how these two can be bridged. The Now-Wow-How approach stems from the Future workshop approach, that is part of the social innovation field (Jungk and Müllert, 1987). Both approaches imply a critical examination of the existing - "what is" - and a creative envisioning of an alternative future - "what might be" (Wikberg Nilsson, 2012).

The norm-creative design approach involves experts and local actors in a two-step process of co-creating alternatives to excluding norms in organizations and society (Wikberg Nilsson and Jahnke, 2018). The first step - norm-critical analysis - encompasses joint identification of and critical reflection on social norms that contributes to inequalities and social exclusion. The second step - norm-creative innovation - encompasses joint development of solutions that counteract such norms through design thinking of what might be. This enables iterative exploration of multiple perspectives and action potentials in co-creative processes, through human-centered design.

\section{Research design}

To investigate co-creative place innovation in Kiruna's city center relocation, three empirical cases are studied and compared. The first case took place during 2015-2016, in the form of an R\&D project aimed at delineating local perceptions and visions of attractive and socially sustainable urban environments in Kiruna's city center relocation, using a Living Lab approach. The second case took place from 2017 to 2018, in the form of a R\&D pre-study aimed at formulating design principles for inclusive and attractive urban design in Kiruna's city center relocation, using a Norm-creative design approach. The third case also took place from 2017 to 2018, in the form of an R\&D project aimed at developing new knowledge and concepts of cross-industrial synergies for city center attractiveness in Kiruna's city center relocation, using a Now-Wow-How approach. These three cases were selected due to their esteemed potential to provide multifaceted insights into various co-creative approaches for urban transformation in the Arctic. The primary criterion for the selection was thus relevance, rather than randomness, as recommended in previous literature on comparative case studies (Wiebe et al., 2010; Yin, 2009). The academic value of comparing these cases is the potential distinction of patterns, similarities and differences in practical approaches for co-creative place innovation. An overview of the cases is presented in Table 1.

A participatory research approach was applied in the studied cases, where new knowledge and ideas are jointly developed by researchers and local actors (Aagaard Nielsen and Svensson, 2006). The main categories of involved actors were residents, civil servants, entrepreneurs and civil society organizations (CSOs) [1]. The value of applying a participatory approach was to achieve both scientifically and societally informed insights into the studied topic of co-creative place-innovation. It thus contributed to the pragmatic and democratic validity of the study. In participatory research, the researchers' traditional role as experts is expanded to facilitators and dialogue partners. The local actors' traditional 
JPMD

13,4

452

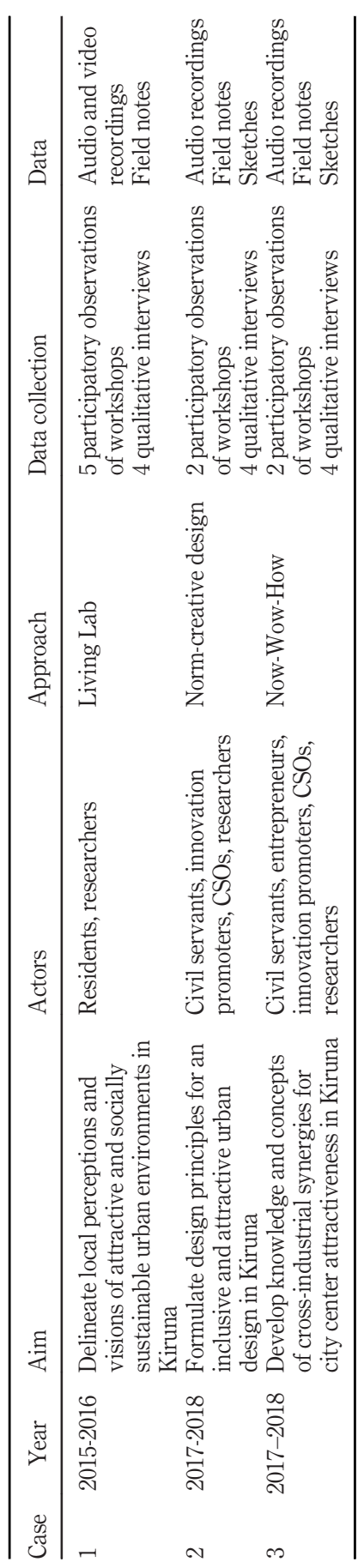

Table 1.

Overview of cases and research design 
role as informants is simultaneously expanded to experts on their own experiences of the studied topic. This is similar to the "mix up" of the traditional roles of designers and local actors/users in co-creative design processes (Sanders and Stappers, 2008). In the studied cases, the expanded roles were intended to enhance the co-production of new knowledge and ideas in the studied cases, by bringing research and practice closer together.

The data from the first case emanates from five co-creative workshops, collected by two of the authors through participatory observations at the workshops, documented in audio and video recordings, and field notes. The workshops aimed to delineate local residents' an arctic town perceptions and visions for attractive urban environments in Kiruna's city center relocation. The workshops involved researchers in architecture and sociology, as well as residents of different age, gender, social backgrounds and family situations. The researchers planned and facilitated the workshops, by guiding the participants through queries and tasks regarding their perceptions and visions for attractive urban environments in Kiruna. They applied the approach of Living Lab, to formulate joint visions and generate new ideas through resident involvement. The workshops were complemented with semi-structured qualitative interviews with four of the workshop participants; these were documented in audio recordings.

The data from the second case emanates from two co-creative workshops, collected by two of the authors through participatory observations at those workshops, and documented in field notes and sketches produced by the participants. The workshops aimed to formulate design principles for inclusive and attractive urban design, based on insights from Kiruna's city center relocation. The workshops involved researchers in design, architecture and urban planning, innovation promoters, representatives from disability CSOs, as well as civil servants from the Region of Norrbotten and Kiruna municipality's departments of Building, Property Management, Technical Services, Leisure and Recreation, Culture, and Social Care and Welfare. The researchers planned and facilitated the workshop, based on a Normcreative design approach, that enabled norm-critical identification of excluding norms and norm-creative formulation of principles for Kiruna's city center relocation. The workshops were complemented with four semi-structured qualitative interviews with experts and residents; these were documented in field notes.

The data from the third case emanates from two co-creative workshops, collected by three of the authors through participatory observations at these workshops, and documented in field notes and sketches produced by the participants. The workshops aimed to develop new concepts for Kiruna's city center relocation through innovative synergies between various industries, actors and components. The workshops involved innovation researchers, innovation promoters, representatives from Kiruna municipality, CSOs, the major mining company, as well as local entrepreneurs in the service sector (tourism, retail, culture, design). The workshops were planned by the researchers and innovation promoters. The latter also facilitated the workshop, by guiding the participants through the co-creative process and by presenting principles and examples of place innovation. A Now-Wow-How approach was applied, to jointly envision new concepts for Kiruna's city center relocation. The workshops were complemented with four semi-structured qualitative interviews with the municipality's industrial manager and the urban planning coordinator; these were documented in audio recordings.

The data from each case was first analyzed separately by the authors. The data from all cases was then analyzed jointly by all authors. A thematic analysis approach was used in both steps to distinguish recurrent themes in the data sets (Guest et al., 2012). The themes were identified manually through thorough readings of transcripts, field notes and sketches. In the separate analysis of the cases, the findings were clustered in line with the main focus 
JPMD 13,4

area of each process - i.e. local perceptions and visions of attractive and socially sustainable urban environments in the first case, design principles for an inclusive and attractive town in the second case, and cross-industrial synergies for city center attractiveness in the third case. In the joint analysis, the findings from each case were clustered in line with the ambition to investigate applied approaches for co-creative place innovation in Kiruna's city center relocation. The elucidated themes were then analyzed in the light of previous studies of inclusive urban transformation.

\section{Kiruna's city center relocation}

Kiruna is a town with 18,000 residents, situated in Sweden's northernmost and most rural region. The region is characterized by its harsh climate, sparse population, long distances and scarce infrastructure. According to the traditions of the indigenous Saami population, the region has eight seasons: winter, spring-winter, spring, pre-summer, summer, preautumn, autumn and pre-winter. The Saamis are since long living and conduct reindeer herding in the region, but Kiruna was not established as a town until 1905, when mineral extraction was initiated in the area (Granås, 2012; Nilsson, 2009; Nilsson 2010a). Most residents in Kiruna have since been directly or indirectly dependent on the mining industry for their livelihood. The municipality is formally the biggest employer in Kiruna, but the mining company, its subcontractors and dependent businesses provide significant employment taken together. The mining industry has traditionally employed primarily male residents from the region, often performing hard physical labor underground. This has started to change during the past decades, due technological and social advancements. The mining work is increasingly automatized and digitalized, the workforce is increasingly commuting from other regions, and more women are employed. Alternative industries such as tourism, space and high-tech have simultaneously grown in the region.

Kiruna is since 2004 planning and managing the relocation of its city center, due to mining-related ground deformation (Granås, 2012; Nilsson, 2010a; Nilsson, 2009, 2010b; Sjöholm, 2016, 2017). The relocation is by public authorities depicted as a transition into a sustainable "model town", thus updating the historical "ideal town" ambitions when Kiruna was established in 1905 (Granås, 2012; Nilsson 2010a; Nilsson, 2009; Sandberg and Rönnblom, 2016). It is acknowledged that Kiruna municipality is formally responsible for developing and implementing a comprehensive plan for the relocation, due to the Swedish municipal planning monopoly. As part of this, they are required to involve the local community in the planning process, including citizens, industries and other actors (Nilsson, 2010b). Researchers from various disciplines - e.g. architecture, sociology, ethnology, design and gender - have continuously studied the relocation process (Granås, 2012; Hidman, 2018; Nilsson, 2010a; Nilsson, 2009, 2010b; Sandberg and Rönnblom, 2016; Segerstedt and Abrahamsson, 2019; Sjöholm, 2016, 2017).

The complex context for the spatial planning of the future Kiruna is noted in several studies, in terms of uncertainties around the global demand for iron-ore, housing market developments, growth of complementary industries besides mining, as well as reactions to change among resident and entrepreneurs (Nilsson, 2009, 2010b; Sandberg and Rönnblom, 2016). The complexity also regards competing interests among various local actors, in regard to cultural heritage, nature preservation, mineral extraction, reindeer herding, tourism, the space industry, etc. (Hidman, 2018; Nilsson, 2009, 2010b; Segerstedt and Abrahamsson, 2019; Sjöholm, 2016, 2017). This is further aggravated by the perception that almost everyone in Kiruna is directly or indirectly dependent on the main mining industry, even though other industries such as tourism, the space industry and high-tech industries have grown during the past decades (Granås, 2012; Nilsson, 2010a). The concerned actors in 
Kiruna's city center relocation are perceived to encompass the municipality, the major mining company, national administrations for roads, railways and aviation, the national heritage board, the regional county administration, CSOs and the local community (Nilsson, 2009, 2010b). Several studies have scrutinized the reactions and interactions among these actors in relation to the relocation plans (Hidman, 2018; Nilsson, 2010a; Nilsson, 2009; Sandberg and Rönnblom, 2016; Sjöholm, 2016, 2017). One study distinguishes four main images of Kiruna among residents, policymakers and media: two rather pessimistic and realistic ones - the dark mining Kiruna and the deformed Kiruna - and two more visionary ones - the space age Kiruna and the new Kiruna (Nilsson, 2009).

There is a noted discrepancy between the optimistic emotions expressed in public communication and the personal concerns of Kiruna's residents, who express ambivalence towards the personal consequences of the relocation and worries regarding where to live (Sandberg and Rönnblom, 2016). The depoliticized approach of the planning process, emphasizing dialogue and common interest rather than political dispute, leaves little room for such ambivalence - and even less for questioning the necessity of the relocation at all. As part of this, public visions of the future Kiruna depict the relocation process as an opportunity to become more attractive to existing and potential residents (Hidman, 2018), emphasizing social equality where "all people, irrespective of (ethnic) background, will be safe and feel a sense of security" and "total openness and total accessibility should be guidelines for everything that concerns the new Kiruna" (Nilsson, 2010a, p. 436). This reflects historic equality ambitions when Kiruna was established in 1905, envisioning "an attractive community" and "a democratic society" through "appealing architecture, sound education and good working conditions" (Sandberg and Rönnblom, 2016, p. 51). The importance of gender equality is prominent on the contemporary policy agenda, where young women are considered as especially crucial to involve in the planning of the future Kiruna, due to their overrepresentation among out-migrators (Nilsson, 2010a). The general image of the "iconic" Kiruna resident is a working-class man, with an outdoor lifestyle of hunting, fishing and snowmobiling, leaving little room for more diverse identities and lifestyles (Granås, 2012). The relocation process tends to be managed as a matter of masculine technological logic, mainly involving male-dominated professions and thus favoring traditional masculine interests (Nilsson, 2010a).

\section{Comparing co-creative place innovation in Kiruna}

The three cases share the co-creative approach of involving local actors in the envisioning of an inclusive and attractive Kiruna during and after the city center relocation. In the first case, local perceptions and visions of attractive and socially sustainable urban environments in Kiruna's city center relocation were jointly delineated by residents and researchers. In the second case, design principles for an inclusive and attractive Kiruna in regard to the city center relocation were jointly formulated by civil servants, CSOs and researchers. In the third case, new knowledge and concepts of cross-industrial synergies for city center attractiveness during Kiruna's city center relocation were developed by civil servants, the mining company, service sector entrepreneurs, CSOs and researchers. The studied cases thus harnessed the city center relocation as an opportunity to make Kiruna more attractive to residents and visitors.

We are dedicated to improve our understanding of what makes a city center attractive for both residents and visitors [...] Kiruna is too small for upholding restaurants, retail and cultural activities for residents only. We depend on finding innovative concepts that align resident and visitor demands. 
JPMD

13,4

(Civil servant interviewed in the third case)

The opportunity-oriented approach to improved attractiveness is in line with previous studies of innovative transformation of Arctic characteristics and challenges into attractions. It is also in line with the public policy agenda in Kiruna that conceptualizes the city center relocation as an opportunity to improve the town's attraction in regard to existing and potential residents and visitors. The focus on improving Kiruna's attractiveness echoes contemporary and historic aspirations of conceptualizing and configuring Kiruna as a "model town", with universally beneficial social improvements in mind. As underlined in previous studies, such a depoliticized approach - with a unifying social agenda based on seemingly common interests - risks concealing diverging interests in regard to Kiruna's urban transformation. The studied cases do however challenge streamlined notions of urban attractiveness by their shared approach of acknowledging and engaging a diversity of actors and perspectives in the envisioning of a future Kiruna. The participants expressed, for example, great pride in Kiruna, at the same time as acknowledging its excluding norms due to the male-dominated traditions of mining, engineering, hunting, fishing, etc. To counteract this exclusion, the cases engaged male and female residents, civil servants, CSOs, the mining company, service sector entrepreneurs and researchers in the envisioning of inclusive solutions for Kiruna's city center relocation. The cases thus align with previous studies of inclusive innovation and design, that highlight the perception that places are produced by local communities as much as by planning professionals.

The sense of community in town should be developed further, beyond what already exists. Even though consensus is hard to imagine it is still important to prevent a major division in the town.

(Resident recorded at a workshop in the first case)

The scope of inclusiveness varies, however, between the studied cases. The first case primarily involved local residents, in line with the previously noted trend of involving citizens in planning processes. The second case did not directly involve residents, but it nevertheless bridged municipal departments and societal sectors by involving a wide range of civil servants and disability CSOs, in line with the similarly noted trend of cross-organizational/sectorial cooperation in urban planning. The third case also had no direct involvement from residents, primarily engaging civil servants, CSOs, the mining company and local entrepreneurs, in line with the noted industrial transformation in Arctic regions with expanding service industries and transforming extraction industries.

Even if the three cases, taken together, involve almost all of the actors that in previous studies are distinguished as concerned with Kiruna's city center relocation, their scope of inclusiveness is not as all-encompassing as in previous studies of inclusive innovation and design. A wider scope of actors, industries and societal sectors are therefore considered crucial to discern a place's multifaceted identity and to design inclusive configuration, content and communication of the place. The competing interests among various actors - concerning, for example, cultural heritage, nature preservation, mineral extraction, reindeer herding and tourism - acknowledged in previous studies of Kiruna, are to some extent addressed in the studied cases. This can be compared to the formal planning process of Kiruna's relocation, where competing interests are subject to a deliberate - although delicate - balancing act. In the first case, previously noted discrepancies between residents and urban planning professionals when defining and experiencing attractiveness, were handled by involving only residents in the 
delineation of local perceptions and visions of attractive urban environments in Kiruna, communicating the results to urban planners in parallel. In the second case, previously noted discrepancies between the optimistic and consensus-oriented communication from local authorities and the more ambivalent concerns among Kiruna's residents, were handled by involving both civil servants and CSOs. Conflict of interest between mining and other industries in Kiruna's city center relocation, also highlighted in previous studies, were in the third case bridged by involving both the major mining company and smaller service sector entrepreneurs in the second workshop.

It is vital to reach relevant stakeholders with proper information in order to address public concerns in regard to the city center relocation [...] It is also vital, but challenging, to practically engage all stakeholders in the process. Some are very eager to participate - for example some entrepreneurs in retail and tourism - while others are more reluctant. It is difficult to estimate if the public interest is truly represented or if some people's needs aren't voiced.

(Civil servant interviewed in the third case)

All of the studied cases involved researchers in the processes, which is coherent with their applied approaches of participatory research and co-creative design. It also concords with the ongoing industrial transformations in Arctic communities, noted in previous studies, by combining expertise in industrial engineering and social science. As the researchers planned - and in the first two cases also facilitated - the workshops, they had considerable influence over the applied approaches. Based on their areas of expertise, the researchers applied a Living Lab approach in the first case, a Norm-creative design approach in the second case, and a Now-Wow-How approach in the third case. As part of these approaches, the workshop participants were guided through queries and tasks regarding their perceptions and visions for attractive urban environments in the first case, for inclusive urban design in the second case and for city-center synergies in the third case. The approaches thereby enabled the participants to critically assess and envision a renewed Kiruna from a diversity of perspectives. This resulted in a number of envisioned solutions for Kiruna's city center relocation, described below.

Envisioned solutions in the first case took the form of five categories of attractiveness:

(1) Architecture and Construction - combining new and old buildings to reflect Kiruna's architectural and social traditions;

(2) Culture and History - preserving and refining places that reflect Kiruna's cultural and historical identity;

(3) Service and Communication - more vibrant meeting places and public transports in Kiruna;

(4) Nature - preserving and harnessing Kiruna's natural surroundings during all eight seasons; and

(5) Environment and Sustainability - sustainable construction and multiple usage of buildings in Kiruna's city center.

Further envisioned solutions were a variance of buildings in regard to size, color and historical eras, a mix of formal and informal meeting places, joint venues for sports and cultural activities, as well as collectively owned green and open plots.

It is important that the new Kiruna functions practically through all eight seasons. Snow clearance, proximity to recreation, shopping, culture, communications, etc. (Resident recorded at a workshop in the first case) 
JPMD

13,4

Envisioned solutions in the second case took the form of five principles for inclusive urban design in Kiruna's city center relocation:

(1) safe places in regard to people's everyday experiences of vulnerability;

(2) useful places in regard to people's (dis)abilities and interests;

(3) inclusive places in regard to social participation and collective commitment;

(4) attractive places in regard to the preferences among a diversity of people; and

(5) healthy places in regard to well-being among a diversity of people.

Further envisioned solutions were a diversity of buildings, car-free streets, easy-access transportation year-round, accessible natural surroundings, cultural activities and extended collaboration across municipality divisions. The participants thereto conceptualized inclusive urban design in terms of transformed mindsets, to make inclusiveness the standard, rather than the exception. They argued for personalization rather than "one size fits all", to meet people's varying needs and (dis)abilities.

Envisioned solutions in the third case took the form of five concepts for cross-industrial synergies in Kiruna's city center:

(1) Snow Chaos 2.0 - an innovative transformation of Kiruna's winter season challenges into a creative snow lab for residents and visitors in the old city center;

(2) Virtual Moose Towers - replicas of moose hunting towers on local hills, where digital control panels enable the user to shift the view of Kiruna's city center from the past to the future;

(3) Mt Luossa - transformation of a decayed hotel facility on a local mountain into a digital leisure hub with VR/AR [2]-based skiing and trekking, accessible to all users regardless of (dis)abilities;

(4) Old City for All - digitally guided walks through Kiruna's old city center, using QR-codes to reenact forgotten stories and memories in the users' mobile phones, especially from women and children whose experiences seldom have been highlighted in local storytelling; and

(5) Kiruna Book Festival 2.0 - an innovative renewal of the existing literature festival, offering VR/AR-based activities that connects local novels and storytelling to specific places in the city center, to especially attract young people.

The envisioned solutions innovatively exploit Kiruna's identity as an Arctic town characterized by a harsh winter climate, vast natural surroundings, traditional extraction industries, expanding service industries and social change. These characteristics are transformed into ideas for new configuration, content and communication of Kiruna's city center during and after the relocation, intended to be attractive and accessible for a diversity of residents and visitors. The cases thereby combine insights from previous studies of place innovation - where place identity provides a basis for innovative synergies between the place's actors, components and processes - and inclusive innovation and design - where excluding patterns and norms related to social factors such as gender, ethnicity, disability and age are identified and counteracted. The cases have thus been able to address and harness both the pessimistic, realistic and visionary images of Kiruna's city center relocation distinguished in previous research. This is achieved through the application of the approaches of Living Lab, Now-Wow-How and Norm-creative design in the cases. 
We should keep what's best with Kiruna and develop it further. I don't want the town to become a Stockholm [3]-wannabe.

(Resident recorded at a workshop in the first case)

\section{Conclusions}

By comparing the three cases of co-creative processes for place innovation in Kiruna's city center relocation, the current study contributes with insights regarding how co-creation can facilitate renewal of an Arctic town. The study reveals that the studied cases have harnessed the city center relocation as an opportunity to make Kiruna more attractive to residents and visitors, by acknowledging and enforcing their sense of place and place-related wellbeing. Although echoing contemporary and historic aspirations of conceptualizing and configuring Kiruna as a "model town", the cases challenge streamlined notions of urban attractiveness. This is achieved by their shared approach of acknowledging and engaging a diversity of actors and perspectives in the envisioning of the future Kiruna. Competing interests between residents and planning professionals, between mining and services industries, and between the local authorities' optimistic and consensus-oriented communication and the more ambivalent concerns among residents in regard to the city center relocation, were addressed by involving various combinations of residents, civil servants, CSOs, the mining company, service sector entrepreneurs and researchers in the processes.

The applied approaches of Living Lab, Now-Wow-How and Norm-creative design enabled the participants to identify excluding patterns and norms in Kiruna's relocation process, and to envision inclusive and attractive (re-)configurations and (re-) conceptualizations for the future Kiruna. The envisioned solutions took the form of categories for attractiveness, principles for inclusive urban design and concepts for crossindustrial synergies. The concepts, principles and categories innovatively exploit Kiruna's identity as an Arctic town characterized by harsh winter climate, vast natural surroundings, traditional extraction industries, expanding service industries and social change. These characteristics are transformed into ideas for new configuration, content and communication of Kiruna's city center during and after the relocation, intended to be attractive and accessible for a diversity of residents and visitors.

The results from the study add to the academic strand of inclusive urban transformation, by providing insights into co-creative processes for re-imagining an Arctic town in times of industrial and social change. In regard to previous studies of local actor involvement in urban transformation (Arefi, 2014; Brandsen et al., 2016; Chapman et al., 2017, 2018; Davies, 2015; Lindberg et al., 2018; Thomas, 2016), the study acknowledges the importance of cocreation by experts and local actors to overcome historical patterns of exclusion of some groups and perspectives in urban planning. This especially concerns the depoliticized "model town" approach and masculine norms in Kiruna's relocation process. The study provides insights into the prerequisites for such inclusion, when relocating an entire city center in the rural Arctic. Critical here is which categories of local actors that are relevant to include, what range of perspectives and interests that are crucial to consider, and what approaches that can be applied to collectively envision inclusive and attractive (re-) configurations and (re-)conceptualizations.

In regard to previous studies of inclusive urban transformation (Arefi, 2014; Brandsen et al., 2016; Chapman et al., 2017, 2018; Davies, 2015; Lindberg et al., 2018; Thomas, 2016), the study provides insights into how the geographical, industrial and cultural identity of an Arctic town can be harnessed to envision new configuration, content and communication that is attractive and accessible for a diversity of residents and visitors, regardless of their gender, age, origin, 
JPMD

13,4

(dis)abilities and other social factors. The study distinguishes how this can be conceptualized in concepts, principles and categories for re-designing the physical configuration, the commercial, public and non-profit content, as well as the internal and external communication of rural towns and cities. This includes reconfigurations that are intended to be safe, useful, inclusive, attractive, interactive, healthy and activating for various groups of people. The study especially points out how the traditional "model-town" conception of an attractive Arctic town can be innovatively transformed into a matter of "urban design for all". This indicates that transcended mindsets regarding norm-critical/creative perspectives and approaches of urban transformation is a crucial mechanism for co-creative place innovation.

The results may be applicable beyond Kiruna and the Arctic, as co-creative urban transformation is crucial for tackling general challenges in rural areas, in terms of long distances, scarce infrastructure, sparse population, as well as industrial and social change. By providing insights into practical processes of co-creation by experts and local actors, the results help guide the delineation and assessment of challenges and needs from a diversity of perspectives, as well as the envisioning of innovative solutions to these. The results highlight the potential to harness Arctic and rural characteristics in the promotion of urban attractiveness and public well-being. Especially when combined with co-creative identification and transformation of excluding norms and patterns related to social factors such as gender, age, origin and (dis)abilities. This reinforces previous conclusions that economic, political and symbolic transformations impact the configuration and perception of places, just as much as physical ones do (Arefi, 2014; Brandsen et al., 2016; Granås, 2012; Nyseth and Viken, 2009; Thomas, 2016).

\section{Notes}

1. Civil society organizations refers to non-profit organizations, voluntary organizations, and other organizations in "the third sector" of society, besides the public and private sectors.

2. $\mathrm{VR}=$ Virtual Reality, $\mathrm{AR}=$ Augmented Reality

3. Stockholm is the capital of Sweden.

\section{References}

Aagaard Nielsen, K. and Svensson, L. (Eds) (2006), Action Research and Participatory Research, Shaker Publishing, Maastricht.

Aragall, F. and MT, J. (2011), Universal Design: The HUMBLES Method for User-Centred Business, Routledge, London.

Arefi, M. (2014), Deconstructing Placemaking: needs, Opportunities, and Assets, Routledge, Abingdon.

Argiolas, G., Cabras, S., Dessì, C. and Floris, M. (2009), "Building innovative models of territorial governance”, Journal of Place Management and Development, Vol. 2 No. 3, pp. 178-210.

Bernhard, I., Olsson, A.K. and Lundh Snis, U. (2018), "Stakeholder collaboration for place innovation recaps and visions in local re-generation", Paper presented at the 21th Uddevalla Symposium, 14-16 June, 2018, Luleå.

Beza, B.B. and Hernández-Garcia, J. (2018), "From placemaking to sustainability citizenship: an evolution in the understanding of community realised public spaces in Bogotá's informal settlements", Journal of Place Management and Development, Vol. 11 No. 2, pp. 192-207.

Börjesson, E., Isaksson, A., Ilstedt, S. and Ehrnberger, K. (2016), "Visualizing gender: norm-critical design and innovation", in Alsos, G.A., Hytti, U. and Ljunggren, E. (Eds), Research Handbook on Gender and Innovation, Edward Elgar, Cheltenham, pp. 252-273. 
Brandsen, T., Cattacin, S., Evers, A. and Zimmer, A. (Eds) (2016), Social Innovations in the Urban Context, Springer, New York, NY.

Chapman, D., Nilsson, K., Rizzo, A. and Larsson, A. (2018), "Updating winter: the importance of climatesensitive urban design for winter settlements", Arctic Yearbook 2018, University of Lapland, Rovaniemi.

Chapman, D., Nilsson, K., Larsson, A. and Rizzo, A. (2017), "Climatic barriers to soft-mobility in winter: Luleå, Sweden as case study”, Sustainable Cities and Society, Vol. 35, pp. 574-580.

Connell, B., Jones, M., Mace, R., Mueller, J., Mullick, A., Ostroff, E., Sanford, J., Steinfeld, E., Story, M. and Vanderheiden, G. (1997), The Principles of Universal Design: Version 2.0, The Center for Universal Design, Raleigh.

Copus, A., Perjo, L., Berlina, A., Jungsberg, L., Randall, L. and Sigurjónsdóttir, H. (2017), Social Innovation in Local Development: Lessons from the Nordic Countries and Scotland, Nordregio, Stockholm.

Davies, W.K.D. (Ed.) (2015), Theme Cities: solutions for Urban Problems, Springer, New York, NY.

Ebrahimabadi, S., Nilsson, K.L. and Johansson, C. (2015), "The problems of addressing microclimate factors in urban planning of the subarctic regions", Environment and Planning B: Planning and Design, Vol. 42 No. 3, pp. 415-430.

Ericson, A. and Törlind, P. (2013), "A deep dive into creative thinking: the now wow how framework", Proceedings of the 19th International Conference on Engineering Design, Vol. 7, pp. 337-346.

Granås, B. (2012), "Ambiguous place meanings: living with the industrially marked town in Kiruna, Sweden”, Geografiska Annaler: Series B, Human Geography, Vol. 94 No. 2, pp. 125-139.

Guest, G., MacQueen, K.M. and Namey, E.E. (2012), Applied Thematic Analysis, SAGE, Thousand Oaks.

Heeks, R., Foster, R. and Nugroho, Y. (2014), "New models of inclusive innovation for development", Innovation and Development, Vol. 4 No. 2, pp. 175-185.

Hidman, E. (2018), "Attractiveness in urban design: a study of the production of attractive places", Doctoral thesis, Luleå University of Technology.

Johansson, T., Segerstedt, E., Olofsson, T. and Jakobsson, M. (2016), "Revealing social values by 3D city visualization in city transformations", Sustainability, Vol. 8 No. 2, p. 195.

Jungk, R. and Müllert, N. (1987), Future Workshops - How to Create Desirable Futures, Institute for Social Inventions, London.

Källström, L. and Hultman, J. (2018), "Place satisfaction revisited: residents' perceptions of 'a good place to live”, Journal of Place Management and Development, Vol. 12 No. 3, pp. 274-290.

Kavaratzis, M. (2012), "From 'necessary evil' to necessity: stakeholders' involvement in place branding", Journal of Place Management and Development, Vol. 5 No. 1, pp. 7-19.

Kenny, M.J. (2017), "Urban planning in the arctic: historic uses and the potential for a resilient urban future", Arctic Yearbook 2018, University of Lapland, Rovaniemi, pp. 133-146.

Kostenius, C. (2018), "Future health", in Frishammar, J. and Ericson, Å. (Eds), Addressing Societal Challenges, University of Technology, Luleå, pp. 71-85.

Lindberg, M. (2018), "Relating inclusiveness and innovativeness in inclusive innovation", International Journal of Innovation and Regional Development, Vol. 8 No. 2, pp. 103-119.

Lindberg, M., Ericson, Å., Gelter, J. and Karlberg, H. (2015), "Social change through place innovation”, Swedish Design Research Journal, Vol. 13 No. 1, pp. 9-13.

Lindberg, M., Gelter, J. and Karlberg, H. (2017), "Tourism networking for regional place innovation in Swedish Lapland", International Journal of Innovation and Regional Development, Vol. 7 No. 4, pp. 257-272.

Lindberg, M., Johansson, K., Karlberg, H. and Balogh, J. (2018), "Place innovative synergies for city center attractiveness: a matter of experiencing retail and retailing experiences", Urban Planning, Vol. 4 No. 1, pp. 91-105. 
JPMD 13,4

Lundh Snis, U., Olsson, A.K. and Bernhard, I. (2017), "The old town district: not only a scenery backdrop - stakeholders' perspectives in urban re-generation", Paper presented at the 20th Uddevalla Symposium, 15-17 June, 2017, Trollhättan.

Nilsson, K. (2009), "Place reinvention by real changed image: the case of Kiruna's spectacular makeover", in Nyseth, T. and Viken, A. (Eds), Place Reinvention: Northern Perspectives, Ashgate, London.

Nilsson, B. (2010a), "Ideology, environment and forced relocation: Kiruna - a town on the move", European Urban and Regional Studies, Vol. 17 No. 4, pp. 433-442.

Nilsson, K. (2010b), "Complexity in spatial planning practice and theory: the case of Kiruna mining town", in de Roo, G. and Silva, E.A. (Eds), A Planner's Encounter with Complexity, Routledge, London, pp. 63-79.

Nilsson, K. (2017), “The history of Swedish planning”, in Kristjánsdóttir, S. (Ed.), Nordic Experiences of Sustainable Planning: Policy and Practice, Taylor and Francis, pp. 127-137.

Nordregio (2016), Co-Creating Attractive and Sustainable Urban Areas and Lifestyles: Exploring New Forms of Inclusive Urban Governance, Nordregio, Stockholm.

Nyseth, T. and Viken, A. (Eds) (2009), Place Reinvention: Northern Perspectives, Ashgate, Farnham.

Olsson, A.K. and Bernhard, I. (2018), "Residents' attitudes towards city transformation - place development in a smaller Swedish city", Paper presented at the 21th Uddevalla Symposium, 14-16 June, 2018, Luleå.

Preiser, W.F.E. and Ostroff, E. (Eds) (2001), Universal Design Handbook, McGraw-Hill, New York, NY.

Sandberg, L. and Rönnblom, M. (2016), "Planning the new city-emotional reaction and position", Emotion, Space and Society, Vol. 21, pp. 50-57.

Sanders, E.B.N. and Stappers, P.J. (2008), "Co-creation and the new landscapes of design”, CoDesign International Codesign, Vol. 4 No. 1, pp. 5-18.

Segerstedt, E. and Abrahamsson, L. (2019), "Diversity of livelihoods and social sustainability in established mining communities", The Extractive Industries and Society, Vol. 6 No. 2, pp. 610-619.

Sjöholm, J. (2017), "Authenticity and relocation of built heritage: the urban transformation of Kiruna”, Journal of Cultural Heritage Management and Sustainable Development, Vol. 7 No. 2, pp. 110-128.

Sjöholm, J. (2016), "Heritagisation, re-heritagisation and de-heritagisation of built environments: the urban transformation of Kiruna, Sweden", Doctoral thesis, Luleå University of Technology.

Ståhlbröst, A. (2012), "A set of key-principles to assess the impact of living labs", International Journal of Product Development, Vol. 17 Nos 1/2, pp. 60-75.

The European Institute for Design and Diversity (2020), "Website "what is DfA", available at: www. dfaeurope.eu/what-is-dfa (accessed 7 April 2020).

Thomas, D. (2016), Placemaking: An Urban Design Methodology, Routledge, New York, NY.

Wiebe, E., Mills, A.J. and Durepos, G. (2010), Encyclopedia of Case Study Research, Sage Publications, Los Angeles.

Wikberg Nilsson, Å. and Jahnke, M. (2018), “Tactics for norm-creative innovation”, She Ji: The Journal of Design, Economics, and Innovation, Vol. 4 No. 4, pp. 375-391.

Wikberg Nilsson, Å. (2012), "Re-thinking designing - collaborative probing of work and workplace change", Doctoral dissertation, Luleå University of Technology, Luleå.

Yin, R.K. (2009), Case Study Research: Design and Methods, SAGE, London. 


\section{Further reading}

Brańka, S., Coca-Stefaniak, A. and Plichta, J. (2016), "City centres as places for strategic cooperation through active city management. The significance of trade entities", Scientific Annals of Economics and Business, Vol. 63 No. 1, pp. 133-141.

Coca-Stefaniak, A. and Carroll, S. (2015), "Traditional or experiential places? Exploring research needs and practitioner challenges in the management of town centres beyond the economic crisis", Journal of Urban Regeneration and Renewal, Vol. 9 No. 1, pp. 35-42.

Hart, C., Stachow, G. and Cadogan, J.W. (2013), "Conceptualising town centre image and the customer experience", Journal of Marketing Management, Vol. 29 Nos 15/16, pp. 1753-1781.

Johnson, K.K., Kim, Y.H., Mee Mun, J. and Lee, J.Y. (2015), "Keeping customers shopping in stores: interrelationships among store attributes, shopping enjoyment, and place attachment", The International Review of Retail. Distribution and Consumer Research, Vol. 25 No. 1, pp. 20-34.

Morandi, C. (2011), "Retail and public policies supporting the attractiveness of Italian town centres: the case of the Milan central districts", Urban Design International, Vol. 16 No. 3, pp. 227-237.

Pazder, D. (2011), "The conception of cultural space revitalization as a way to increase downtown attractiveness", Quaestiones Geographicae, Vol. 30 No. 4, pp. 63-67.

Pressman, N. (2004), Shaping Cities for Winter: climatic Comfort and Sustainable Design, Winter Cities association, City of Prince George.

Wahlberg, O. (2016), "Small town centre attractiveness: evidence from Sweden”, International Journal of Retail and Distribution Management, Vol. 44 No. 4, pp. 465-488.

Weltevreden, J.W.J. and Van Rietbergen, T. (2007), "E-shopping versus city centre shopping: the role of perceived city centre attractiveness", Tijdschrift Voor Economische en Sociale Geografie, Vol. 98 No. 1 , pp. 68-85.

Wikberg Nilsson, A., Blomqvist, K., Jahnke, M., Molnar, S., Nilsson, K.L., de Fine Licht, K. and Öhrling, T. (2018), Tillgänglighetsdesign För Stadens Utveckling, Luleå University of Technology, Luleå.

Zenker, S. (2011), "How to catch a city? The concept and measurement of place brands", Journal of Place Management and Development, Vol. 4 No. 1, pp. 40-52.

\section{Corresponding author}

Malin Lindberg can be contacted at: malin.lindberg@1tu.se

For instructions on how to order reprints of this article, please visit our website: 